\title{
Evaluation of Histopathological Changes in Ducks Infected With Newcastle Disease Virus
}

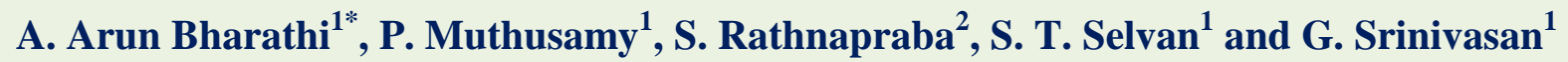 \\ ${ }^{1}$ Department of Poultry Science, Madras Veterinary College, Tamilnadu Veterinary and \\ Animal Sciences University (TANUVAS), Chennai-600 007, Tamil Nadu, India \\ ${ }^{2}$ Department of Animal Biotechnology, Madras Veterinary College, Tamilnadu Veterinary \\ and Animal Sciences University (TANUVAS), Chennai-600 007, Tamil Nadu, India \\ *Corresponding author
}

\section{A B S T R A C T}

Keywords

Newcastle disease virus, Duck, Breed, Susceptibility, Pathogenicity

\section{Article Info}

Accepted: 25 May 2018 Available Online: 10 June 2018
Newcastle disease (ND) is a highly contagious viral disease affecting most of the avian species. The mortality of birds varies with the virulence and pathogenicity of virus that infects the birds and also with susceptibility of birds. Though ducks are resistant to ND, there are some studies reported that the susceptibility of some breeds of ducks to NDV. In this present study, two exotic breeds of ducks (White Pekin and Khaki Campbell) were experimentally infected with $10^{5} \mathrm{Egg}$ Infectious Dose ${ }_{50}$ of velogenic Newcastle Disease Virus (vNDV) by subcutaneous route on $15^{\text {th }}$ day of age to study the pathogenicity of NDV in ducks. The birds were observed for clinical disease and gross pathology. The clinical signs and death were noticed only in Khaki Campbell ducks and not in White Pekin. Clinical signs were primarily neurologic. Tissues were collected from ducks euthanized on $1^{\text {st }}, 3^{\text {rd }}, 7^{\text {th }}$ and $21^{\text {st }}$ day of post infection $\mid$ or after disease associated death. The histopathology of collected tissues was studied by haematoxylin and eosin staining. The results confirmed that some of the NDV virulent strains caused the disease in ducks, and played a role in the epidemiology of ND.

\section{Introduction}

Newcastle Disease (ND) is a highly contagious viral disease of poultry, classified as notifiable disease by World Organisation for Animal Health (OIE). It is caused by Avulavirus belonging to the family Paramyxoviridae. ND virus (NDV) can infect over 200 species of birds, but the severity of disease produced varies with both host and strain of virus. ND ranked as the fourth most important disease in terms of the number of livestock units lost for poultry species, behind highly pathogenic avian influenza, infectious influenza (Anonymous, 2011). The virus strains were classified according to the duration of embryo's death after inoculation of embryonated eggs, with those strains that caused death the fastest (and therefore more virulent) termed velogens and those in which the embryos survived for much longer periods of time termed lentogens. Those strains falling in between were called mesogens (OIE, 2008).

Geese and ducks are considered as the natural 
reservoir of NDV and research has shown that virulent NDV can causemortality in some ducks (Shi et al., 2011). Yabin Dai et al., (2014) reported that the Mallard ducks appeared to be the most susceptible, where the Pekin ducks was the most resistant to NDV infection among 6 breeds of ducks (Mallard, Gaoyou, Jinding, Shaoxing, Shanma \& Pekin). Nishizawa et al., (2007) observed that White Pekin ducks were resistant to the development of ND clinical signs when challenged with velogenic NDV and reported that vaccination is essential to reduce elimination of virus.

Zhang et al., (2011) infected the ducks with NDV/Duck/China/GD09-2/2009 and NDV/ Duck/China/SD09/2009 and noticed the histopathological changes includes villus missing and necrosis of epithelial cell infiltration in the intestine, lymphocytes infiltration and venous congestion in liver, necrosis of massive tissue in spleen.

Lu et al., (2014) reported that moderate to severe lymphoid necrosis was detected in the spleen of geese infected with NDV by HE staining at $2^{\text {nd }}$ and $4^{\text {th }}$ d.p.i.

Regeneration of the white pulp and congestion or haemorrhages in red pulp were observed by $6^{\text {th }}$ d.p.i. At later stage, the number of apoptotic cells started to decrease. There was no distinct demarcation line in white pulp and red pulp.

Anis et al., (2012) infected the ducks and chicken with 9a5b NDV intranasally and observed the apoptosis mainly within the germinal centres of spleen whereas in chicken, numerous apoptotic cells in the periellipsoidal white pulp and the peri-ellipsoidal, peri-arteriolar and peri-venous lymphoid sheaths. In thymus and bursa, lymphoid deletion was the main feature of chicken, but only apotosis was noticed in duck thymus and bursa.

\section{Materials and Methods}

\section{Virus}

The challenge virus used was a velogenic NDV strain isolated in 10-day-old specificpathogen-free chicken embryonated eggs.

Amnio-allantoic fluid samples were harvested and stored at deep freezer $\left(-20^{\circ} \mathrm{C}\right)$ for further use. The confirmation of virus in the allantoic fluid was performed by Haemagglutination test and also by polymerase chain reaction using Haemagglutinin Neuramidase (HN) gene primers. The virus challenge dose used was $10^{5}$ egg infectious dose $_{50}$ per bird, calculated using the Reed and Muench method (Reed \& Muench, 1938).

\section{Birds}

This study was approved by the Institutional Approval of Ethical Committee (IAEC). The two duck breeds used for this study were White Pekin $(n=25)$ and Khaki Campbell ducks $(n=25)$.

Each breed was divided into two groups includes Group $1(\mathrm{n}=10)$ and group $2(\mathrm{n}=$ 15) as control ducks and infected ducks, respectively. Feed and water were provided ad libitum. After 2-week period of acclimatization, the ducks in group 2 were injected subcutaneously with the virus.

\section{Sampling}

The ducks from infected group that showed severe clinical signs and ducks in the control group were euthanized by cervical dislocation at $1^{\text {st }}, 3^{\text {rd }}, 7^{\text {th }}$ and $21^{\text {st }}$ day of post infection. The lung, spleen, proventriculus, intestine and liver tissues from the control group were collected and fixed immediately by immersion in $10 \%$ neutral buffered formalin for at least 24 hour for histopathology. 


\section{Histopathological study}

The representative tissue samples of various target organs (Lungs, Liver, Proventriculus, Intestine and Spleen) were collected in 10\% neutral buffered formalin in labelled bottles during necropsy and preserved for atleast 24 hours before processing.

The collected tissues were subjected to alcohol-xylene protocol for 16 to 18 hours duration for dehydration and clearing of tissues. Before subjecting it to processing, the tissues were trimmed into smaller section and washed under running tap water for 2-3 hours to remove the preservatives from the tissues.

The washed tissues were placed in 50\% absolute alcohol for 4hoursfor removal of fixative and initiation of dehydration of tissues. Further, the tissues were subjected to series of ascending grades of alcohol $(70 \%$, $80 \%, 90 \%$ ) for 2 hours each and finally absolute alcohol for 2 hours.

Later, the tissues were kept in xylene for 3 changes of 2 hours duration each for removal of alcohol and clearing purpose.

After clearing, the tissues were kept in liquid paraffin for 2-4 hours. Finally, the tissues were embedded in paraffin cassette blocks and were sectioned at $5 \mu \mathrm{m}$ using microtome.

The cut tissue sections were stained by routine Haematoxylin and Eosin protocol and were examined under binocular light microscope.

\section{Results and Discussion}

\section{Clinical disease and gross pathology}

Clinical signs were first observed in infected duck at $2^{\text {nd }}$ d.p.i. consisting of moderate to severe depression with green-white diarrhoea, anorexia and nervous symptoms. Few ducks exhibited overt clinical signs on $3^{\text {rd }}$ d.p.i. Two Khaki Campbell ducks in the infected group exhibited obvious clinical signs including paralysis and opisthotonus, died at $4^{\text {th }}$ d.p.i. White Pekin ducks did not show any clinical signs which was exhibited by Khaki Campbell. From $5^{\text {th }}$ d.p.i., there was reduction in clinical signs and spontaneously no mortality was recorded. Samples were collected from three surviving ducks euthanized to detect the histopathological lesion at $1^{\text {st }}, 3^{\text {rd }}, 7^{\text {th }}$ and $21^{\text {st }}$ d.p.i. respectively. Splenomegaly, haemorrhagic thymus and lungs were observed in infected ducks. The non-infected control ducks appeared normal throughout the experiment.

\section{Histopathology}

\section{Khaki Campbell}

Two Khaki Campbell ducks in the infected group exhibited obvious clinical signs including paralysis and opisthotonus died at $4^{\text {th }}$ d.p.i. Congestion was observed in brain tissues on $3^{\text {rd }}$ d.p.i. (Plate 1a). On $7^{\text {th }}$ d.p.i., congestion (Plate 1b), focal glandular infiltration (Plate 1c) and moderate lymphoid depletion (Plate 1d) were noticed in lungs, proventriculus and liver respectively.

\section{White Pekin}

In White Pekin ducks, the histopathological changes were mild to moderate. In spleen, moderate lymphoid depletion was noticed on $3^{\text {rd }}$ d.p.i. (Plate 2a) and lymphocytolysis and new germinal layer formation was observed on $21^{\text {st }}$ d.p.i. (Plate 2b).On $7^{\text {th }}$ d.p.i., multifocal periportal hepatitis (Plate 2c) and congestion (Plate 2d) were noticed in liver and lungs respectively. Multifocal glandular and mucosal mononuclear cells infiltration was observed in proventriculus on $7^{\text {th }}$ d.p.i. (Plate 2e) and $21^{\text {st }}$ d.p.i. respectively. 
Table.1 Histopathological lesions noticed in different tissues of Khaki Campbell ducks

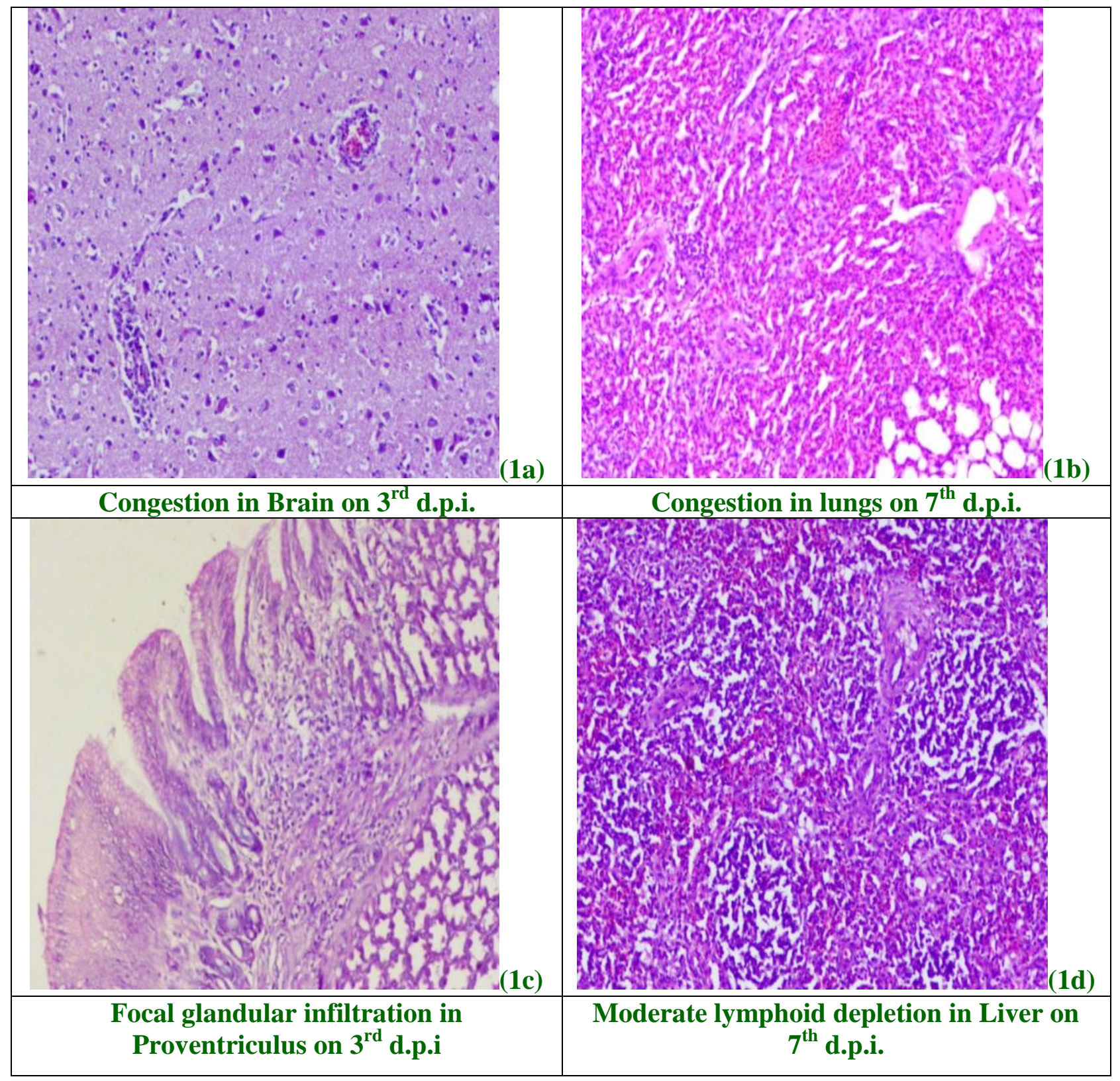

Table.2 Histopathological lesions noticed in different tissues of White Pekin ducks

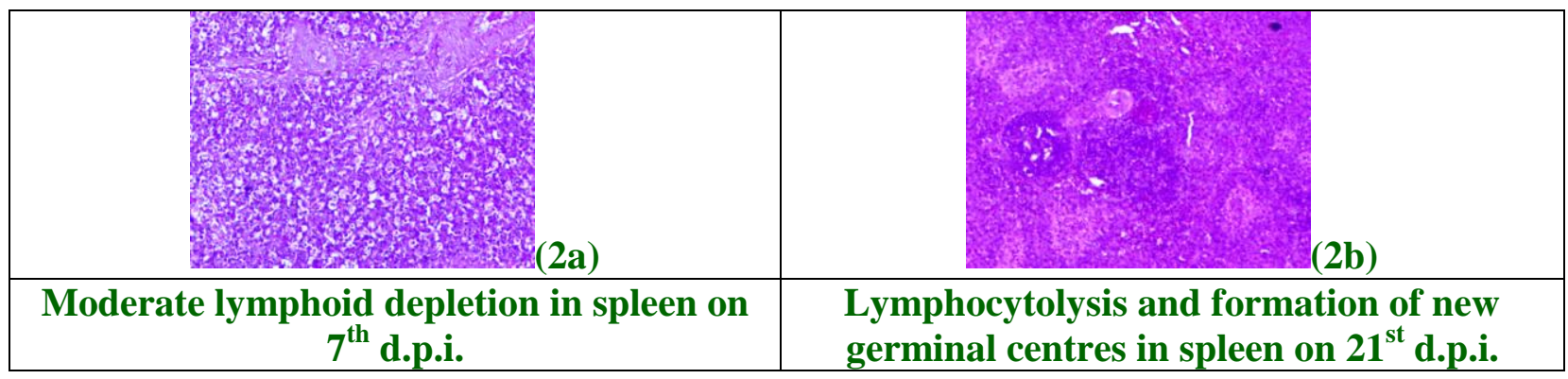




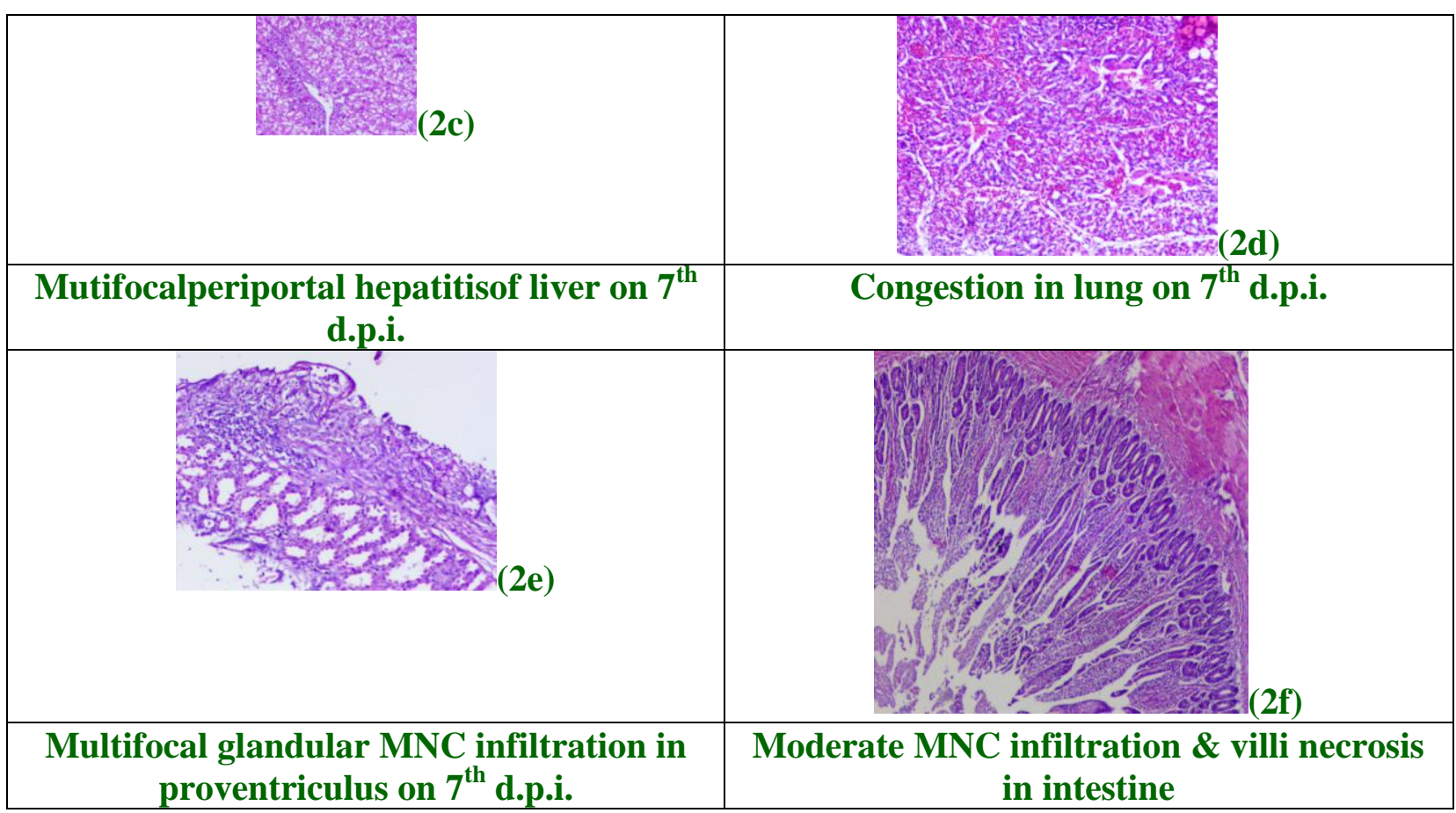

Intestinal villi necrosis and moderate $\mathrm{MNC}$ infiltration was noticed in intestine on $7^{\text {th }}$ d.p.i (Plate 2f).

The present study focused on the histopathological changes in the duck tissues after infecting with velogenic form of Newcastle Disease virus to study the pathogenicity between two breeds of ducks. Among ducks, White Pekin ducks were more resistant to the velogenic form of NDV, while other breeds were less susceptible to the infection (Dai et al., (2014) and Nishizawa et al., (2007)). The severity of disease and mortality was noticed only in Khaki Campbell whereas no mortality was observed in White Pekin.

Khaki Campbell showed the nervous clinical signs including torticollis, unilateral or bilateral leg paralysis, etc and gross lesions detected were haemarrhagic thymus and lungs as reported by Lu et al., (2014) in geese.

The neurologic signs like twisting of head and neck, unilateral or bilateral leg paralysis observed in the ducks infected with NDV in our present study were similar to the clinical signs reported in 15 days old ducks infected with NDV by Dai et al., (2014).

Thegross lesions were usually absent in the birds developing neurological signs such as torticollis, ataxia or a wing or leg paralysis. However, in case of viscerotropic vNDV, hemorrhage and necrosis of lymphoid tissues was present, especially in the intestine, spleen and thymus (Cattoli et al., 2011).

The histopathological lesions seen in White Pekin ducks breed was more when compare to Khaki Campbell as it shown the neurological symptoms like torticollis, leg paralysis, etc. The nervous clinical signs with less gross lesion observed in present study were in agreement with report of Cattoli et al., (2011).

The most remarkable and consistent gross lesion observed in spleen organs was severe lymphoid depletion and necrosis (Lu et al., 2014). The major microscopic lesions observed in the birds affected with NDV in the present study were mild to moderate lymphoid depletion and mononuclear cells 
infiltration. Ducks showed mild lymphoid depletion and severe congestion in spleen on $1^{\text {st }} \quad$ d.p.i whereas lymphocytolysis and formation of new germinal centers was observed on $21^{\text {st }}$ d.p.i. Similarly, Lu et al., (2014) reported moderate to severe lymphoid necrosis in spleen and regeneration of white pulp at $6^{\text {th }}$ d.p.i.

Similar to the report of Goffic et al., (2006) that the low expression of TLR3 in mammals leads to efficient viral replication and decreased lung lesions as no lung lesions observed in Khaki Campbell ducks on $1^{\text {st }}$ d.p.i. might be due to the least expression of TLR3 was observed in Khaki Campbell breed in both lung and spleen tissues.

The less severity of haemarrhagic lesions, lymphoid depletion and necrosis of various tissues might be due to expression of IL2 gene in all the duck breeds as reported by Susta et al., (2015), as IL2 partially decrease the pathogenicity of virus by lessening the tissue damage.

The ducks infected with vNDV showed the villus necrosis and moderate mononuclear cells infiltration in the intestine and multifocal periportal hepatitis in liver was noticed as reported in Zhang et al., (2011) as the duck infected with NDV/Duck/China/GD092/2009 and NDV/Duck/China/SD09/2009 and observed the histopathological changes includes villus missing and necrosis of epithelial cell infiltration in the intestine, lymphocytes infiltration and venous congestion in liver, necrosis of massive tissue in spleen.

Though ducks and geese are considered as natural reservoir and resistant to NDV, some breeds are susceptible to the infection. When comparing between the two ducks breeds, Khaki Campbell is susceptible whereas White Pekin is resistant to the NDV infection.

\section{References}

Anis. Z, T. Morita, K. Azuma, H. Ito, T. Itoand A. Shimada (2013). Histopathological Alterations in Immune Organs of Chickens and Ducks after Experimental Infection with Virulent 9a5b Newcastle Disease Virus. J. Comp. Path., 149: 82-93.

Anonymous, 2011. World Livestock Disease Atlas: A Quantitative Analysis of Global Animal Health Data A (20062009). In: The International Bank for Reconstruction and Development - The World Bank and The TAFS Forum, (Ed.), Washington, DC.

Cattoli, G., L. Susta, C. Terregino and C. Brown, 2011. Newcastle disease: a review of field recognition and current methods of laboratory detection. $J$. vet.diagn. invest. 23(4): 637-656.

Dai, Y., X. Cheng, M. Liu, X. Shen, J. Li, S. Yu, J. Zou and Chan Ding (2014). Experimental infection of duck origin virulent Newcastle disease virus strain in ducks.BMC.Vet. Res. 10: 164.

Goffic, R., V. Balloy, M.L agranderie, L. Alexopoulou, N. Escriou, M. Flavell, R. Chignard, M. Si-Tahar, 2006. Detrimental contribution of the toll-like receptor (TLR) 3 to influenza A virusinduced acute pneumonia. PLoSPathog. 2: 53.

Lu, A., Y. Diao, H. Chen, J. Wang, P. Ge, X. Sun, and D. Hao, 2014. Evaluation of histopathological changes, viral load and immune function of domestic geese infected with Newcastle disease Virus.Avian Pathol.43: 325-332.

Nishizawa, M., A.C. Paulillo, L.S.O. Nakaghi, A.D. Nunes, J.M. Campioni, L. DorettoJúnior, 2007. Newcastle Disease in White Pekin Ducks: Response to Experimental Vaccination and Challenge. Brazilian J. Poul. Sci.9: 77-79. 
OIE, World Organization for Animal Health: Manual of Diagnostic Tests and Vaccines for Terrestrial Animals, 6th ed., pp. 576- 589. OIE, Paris, France, 2008.

Reed, L.J. \& H. Muench, 1938.A simple method of estimating fifty per cent endpoints.Am. J. Epidemiol.27: 493497.

Shi, S.H., Huang, Y., Cui, S.-J., Cheng, L.-F., Fu, G.-H., Li, X., Chen, Z., Peng, C.-X., Lin, F., Lin, J.-S. \& Su, J.-L. (2011). Genomic sequence of an avian paramyxovirus type 1 strain isolated from Muscovy duck (Cairinamoschata) in China. Archives of Virology, 156, 405-412.
Susta, L., Diego G. Diel, Sean Courtney, Stivalis Cardenas-Garcia1, Roy S. Sundick, Patti J. Miller, Corrie C. Brown and Claudio L. Afonso1, 2015. Expression of chicken interleukin-2 by a highly virulent strain of Newcastle disease virus leads to decreased systemic viral load but does not significantly affect mortality in chickens. J. Virol.12:122.

Zhang, S., X. Wang, C. Zhoa, D. Liu, Y. Hu, J. Zhao and G. Zhang, 2011. Phylogenetic and pathotypical analysis of two virulent Newcastle Disease viruses isolated from Domestic Ducks in China. PloS one.6: 25000.

\section{How to cite this article:}

Arun Bharathi A., P. Muthusamy, S. Rathnapraba, S. T. Selvan and Srinivasan G. 2018. Evaluation of Histopathological Changes in Ducks Infected With Newcastle Disease Virus. Int.J.Curr.Microbiol.App.Sci. 7(06): 3768-3774. doi: https://doi.org/10.20546/ijcmas.2018.706.441 